\title{
Type I protein S deficiency and skin necrosis
}

\author{
A. Craig, ${ }^{1}$ D.A. Taberner, ${ }^{1}$ A.H. Fisher, ${ }^{1}$ D.N. Foster ${ }^{2}$ and J. Mitra ${ }^{2}$ \\ ${ }^{1}$ Department of Haematology, Withington Hospital, Manchester and ${ }^{2}$ Birch Hill Hospital, Rochdale, UK.
}

\begin{abstract}
Summary: A kindred with Type I protein S deficiency is described in which the index case developed skin necrosis during induction of oral anticoagulant therapy for deep venous thrombosis. Two other family members with protein $\mathrm{S}$ deficiency have been detected, and demonstrate the clinical variability of this condition.
\end{abstract}

\section{Introduction}

Coumarin-induced skin necrosis is an uncommon complication of oral anticoagulation, seen typically during induction of therapy. It has been described in association with venous thrombosis due to inherited deficiency of protein $\mathrm{C}(\mathrm{PC}) .{ }^{1} \mathrm{PC}$ is a vitamin $\mathrm{K}$-dependent serine protease with an anticoagulant activity directed against clotting factors V and VIII. Protein S (PS), another naturally occuring vitamin K-dependent anticoagulant, acts as a cofactor for PC. PS deficiency has also been described in association with a familial venous thrombotic tendency. Recently, coumarin-induced skin necrosis has been described in association with PS. ${ }^{2}$ We describe a kindred with PS deficiency in which the proposita suffered skin necrosis at the onset of treatment with oral anticoagulants.

\section{Case report}

The patient, a young woman, presented in 1985 at the age of 21 with a history of pleuritic chest pain and a painful swollen left leg. She had been on the oral contraceptive pill for 3 years and was a cigarette smoker. She had had an uneventful pregnancy in 1980-81. A diagnosis of left iliac vein thrombosis and pulmonary embolus was made on clinical grounds; treatment was started with intravenous heparin (40,000 units/24 hours) and a loading dose $(6 \mathrm{mg})$ of nicoumalone was given. She received a total of $12 \mathrm{mg}$ of nicoumalone in divided doses over the first 72 hours.

At the end of this period, when the British Ratio (BR) had risen to 4.9 , the patient began to complain of a burning sensation in the left thigh. An

Correspondence: A. Craig, M.R.C.P., M.R.C. Path Accepted: 22 November 1989 area of discolouration developed on the thigh, with bruising and blistering on the skin, followed by an extensive area of skin necrosis (Figure 1). The dose of nicoumalone was reduced to maintain the BR at $\simeq 2.0$. The necrotic area became infected and a further admission was required for desloughing and skin grafting. Long term anticoagulation was maintained with nicoumalone.

In March 1986 the patient became pregnant again: subcutaneous heparin was substituted for nicoumalone during the last trimester. However, she developed a further pulmonary embolus, and required admission for treatment with full dose intravenous heparin. She subsequently delivered a healthy infant, and there were no haemorrhagic complications. Following delivery, long term anticoagulation with nicoumalone was successfully recommenced.

Investigation demonstrated PS deficiency in the proposita, her mother and one of her two brothers (Table I). The patient's mother is asymptomatic, but the brother has had several episodes of deep venous thrombosis. $\mathrm{He}$ is anticoagulated with warfarin and has had no episodes of skin necrosis. The diagnosis of congenital PS deficiency is difficult in patients receiving oral anticoagulants. In patients stabilized on oral anticoagulants comparison can be made between PS and Factor II levels as both are normally depressed to a similar level. The disproportionately low PS level in the first brother is highly suggestive of congenital PS deficiency. The second brother is asymptomatic and has normal PS levels.

Functional PC was measured using a chromogenic method. ${ }^{3}$ Free PS and C4b-bound PS can be distinguished by two-dimensional immunoelectrophoresis. ${ }^{4}$ This technique showed the presence of normal amounts of C4b-bound protein $S$ in the affected individuals with a marked reduction of the free form. The deficiency was therefore classified as type I. Type II deficiency is 


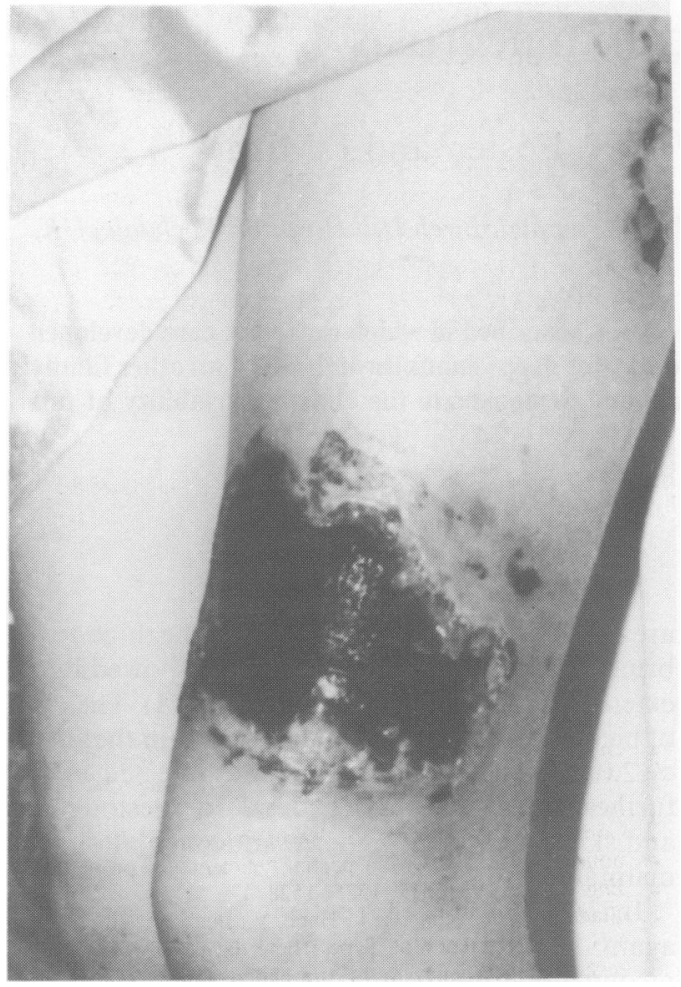

Figure 1 Extensive area of skin necrosis on patient's thigh

characterized by depression of both free and bound forms of PS. ${ }^{4}$

\section{Discussion}

Protein $\mathrm{S}$ is a cofactor for the proteolytic action of activated protein $\mathrm{C}(\mathrm{aPC})$ on the clotting factors $\mathrm{V}$ and VIII. PC is activated by thrombin via thrombomodulin on the endothelial surface. ${ }^{5}$ PC and PS are therefore important naturally occurring anticoagulants, regulating the extension of thrombus formation in vivo. Congenital deficiencies of $\mathrm{PC}^{6}$ and $\mathrm{PS}^{7}$ are well recognized in association with a familial tendency to thrombosis, and are probably the most frequently diagnosed of the familial thrombophilias. ${ }^{8}$ Inheritance is believed to be autosomal dominant: infants with homozygous PC deficiency suffer purpura fulminans which is rarely compatible with life.

Heterozygotes with PC or PS deficiency present classically with deep venous thrombosis and/or pulmonary embolism in the 3rd decade of life, and precipitating factors are absent in $50 \%$ of cases. However, some heterozygotes (for example the mother of our patient) have no history of thrombosis even in the face of accepted risk factors for thromboembolism such as pregnancy or surgery. Indeed our patient had had one baby and then been on the oral contraceptive pill for three years before developing clinical evidence of venous thromboembolism.

The mechanism for the coumarin-induced skin necrosis seen in some patients with PS or PC deficiency is unclear. Following a loading dose of a coumarin anticoagulant, PC and FVII levels fall more rapidly than those of the other vitamin K-dependent factors, reaching a nadir at 46 hours Initial reduction in PS levels may follow a similar time scale. ${ }^{9}$ Thus there is a disproportionate ear decrease in the physiological inactivators of factors $\mathrm{V}$ and VIII while procoagulant activity remains relatively unimpaired. It has been suggested that in PC deficiency a loading dose of coumarin anticoagulant, particularly a short-acting one such as nicoumalone, leads to a major imbalance of clotting factors and a shift towards a procoagulant state. It is postulated that this might lead to thrombosis within the micro-circulation with subsequent skin necrosis. ${ }^{1}$ As PS is an important cofactor for PC it is perhaps not surprising that PS deficiency may also be associated with coumarin-

Table I Coagulation studies

\begin{tabular}{lcccccc}
\hline Subject & $\begin{array}{c}\text { PT } \\
\text { (seconds) }\end{array}$ & $\begin{array}{c}\text { APTT } \\
\text { (seconds) }\end{array}$ & $\begin{array}{c}\text { Free } \\
\text { protein } \\
\text { S antigen }\end{array}$ & $2-D I E$ & $\begin{array}{c}\text { Functional } \\
\text { protein } \\
C\end{array}$ & $\begin{array}{c}\text { Factor } \\
I I \\
(I U / d l)\end{array}$ \\
\hline Patient & 17.5 & 32.0 & $12.5 \%$ & abnormal & $128 \%$ & n.t. \\
Mother & 14.3 & 30.5 & $17.0 \%$ & abnormal & $188 \%$ & n.t. \\
Brother 1 & $28.5^{*}$ & $44.7^{*}$ & $<10.0 \% *$ & abnormal & n.t. & $39.0^{*}$ \\
Brother 2 & n.t. & n.t. & $85 \%$ & normal & n.t. & n.t. \\
Normal & $13.5-17.5$ & $36-48$ & $57-120 \%$ & & $70-130 \%$ & $60-130$ \\
range & & & & & & IU $/$ dl \\
\hline
\end{tabular}

PT = prothrombin time; APTT = activated partial thromboplastin time; 2 -DIE = two dimensional electrophoresis; n.t. = not tested; *subject taking warfarin-note disproportionately low PS compared with PT, APTT and Factor II. 
induced skin necrosis.

The relative changes in the vitamin $\mathrm{K}$-dependent factors are less marked if anticoagulation is initiated using smaller, divided doses of a longacting coumarin drug. ${ }^{6}$ If skin necrosis should occur during induction of anticoagulation, it is generally recommended that heparin be reintroduced and oral anticoagulants reduced to a minimum.

As far as we are aware, formal recommendations have not been made for the management of congenital PS deficiency in pregnancy. Carriers of the defect are at increased risk of thromboembolism particularly during the last trimester and postpartum period, and surveillance should be especially vigilant at these times. 'Vigorous short term prophylaxis' has been recommended in general terms (though not specifically for pregnancy) ${ }^{10}$ but, as indicated by the course of events in our patient, carriers with a past history of venous thromboembolism may not be protected by currently recommended antenatal anticoagulant regimes. However, we are reluctant to recommend heparin throughout pregnancy because of the dangers of osteopenia.

\section{Acknowledgements}

Departments of Medical Illustration, Withington Hospital and Rochdale Hospitals.

\section{References}

1. Broekmans, A.W., Bertina, R.M., Loeliger, E.A., Hofmann, V., \& Klingemann, H-G. Protein C and the development of skin necrosis during anticoagulant therapy. (letter) Thromb Haemost 1983, 49: 244.

2. Grimaudo, V., Gueissaz, F., Hauert, J., Sarraj, A., Kruithof, E.K.O. \& Bachmann, F. Necrosis of skin induced by coumarin in a patient deficient in protein $\mathrm{S}$. Br Med J 1989, 298: 233-234.

3. Odegard, O.R., Try, K. \& Abildgaard, U. Protein C: a simplified semi-automated activity assay. Thromb Res 1986, 42: $257-262$.

4. Comp, P.C., Doray, D., Patton, D. \& Esmon, C.T. An abnormal plasma distribution of protein $S$ occurs in functional protein S deficiency. Blood 1986, 67: 504-508.

5. Lammle, B. \& Griffin, J.H. Formation of the fibrin clot: The balance of procoagulant and inhibitory factors. In: Ruggeri, Z.M. (ed) Clinics in Haematology. W.B. Saunders, Philadelphia 1985, 14:2, 281-342.
6. Griffin, J.H., Evatt, B., Zimmerman, T.S., Kleiss, A.J. \& Wideman, C. Deficiency of protein $\mathbf{C}$ in congenital thrombotic disease. J Clin Invest 1981, 68: 1370-1373.

7. Comp, P.C. \& Esmon, C.T. Recurrent venous thromboembolism in patients with a partial deficiency of protein $\mathrm{S}$. $N$ Engl J Med 1984, 311: 1525-1528.

8. Gladson, C.L., Scharrer, I., Hach, V., Beck, K.H. \& Griffin, JH. The frequency of Type I heterozygous protein $S$ and protein $C$ deficiency in 141 unrelated young patients with venous thrombosis. Thromb Haemost 1988, 59: 18-22.

9. Weiss, P., Soff, G.A., Halkin, H. \& Seligsohn, U. Decline of proteins $C \& S$ and factors II VII IX and $X$ during the intiation of warfarin therapy. Thromb Res 1987, 45: 783-790.

10. Briet, E., Broekmans, A.W. \& Engesser, L. Hereditary protein S deficiency. In: Bertina, R.M. (ed) Protein $C$ and Related Proteins. Churchill Livingstone, Edinburgh, London, 1988, pp. 203-212. 